\title{
DINÂMICA DE MINI-TERMINAIS NO TRÂNSITO: UM ESTUDO DE CASO
}

\author{
P. Godoy' ${ }^{1}$; R. A. Costaㄹ; M. C. Suguinoshita ${ }^{3}$; G. P. Caldeira ${ }^{4}$; L. B. P. Leme'; A. D. Bosco Junior ${ }^{6}$ \\ 1,2,3,4,5,6 Universidade Federal do Paraná, Rua Evaristo F. F. da Costa, 418, Jd. das Américas, CuritibalPR \\ paula.godoy123@gmail.com ${ }^{1}$,roaucosta@gmail.com²,maria.sugui@ufpr.br ${ }^{3}, g a b r i e l c a l d e i r a @ u f p r . b r^{4}$, \\ lucasbudel.leme@gmail.com ${ }^{5}$, alceudalboscojr@gmail.com ${ }^{6}$
}

Resumo: A pesquisa tem como objetivo a avaliação de dois cenários de trânsito - atual e proposto - em uma via arterial no Bairro Jardim das Américas - Curitiba/PR. Este trabalho propóe a implantação de um mini-terminal que integre o trânsito de usuários e a tarifa dos ônibus que atualmente passam pela estação tubo, e das linhas que operam nas vias laterais, esperando uma significativa melhoria na segurança viária e um sistema de transporte mais eficiente.

Palavras-chave: Mini-terminal, Simulação, Transporte público.

\section{Introduçáo}

Mudanças na geometria de redes de transporte visando maior segurança são geralmente impopulares e fontes de críticas por parte dos usuários de veículos motorizados. Isso ocorre muitas vezes por falta de clareza na tomada de decisão, levando a uma falsa premissa de que o aumento de segurança é desnecessário e afeta a mobilidade negativamente [1]. Nesse sentido, o uso da microssimulação vem como um meio de facilitar essa tomada de decisão de forma mais eficaz, possibilitando inclusive um melhor entendimento dos projetos [2]. A proposta estudada neste artigo será a mudança, essencialmente, da dinâmica dos ônibus do transporte público: deseja-se modificar o layout atual da disposição das paradas de ônibus introduzindo um mini-terminal de transporte público, onde todas as entradas e saídas dos veículos estariam concentradas em uma única região limitada.

\section{Metodologia}

Foram utilizadas contagem de tráfego obtidas do IPPUC - Instituto de Pesquisa e Planejamento Urbano de Curitiba e também realizada pela equipe, além de medições de fila pelo método prescrito no HCM. Dados de infraestrutura foram observados com auxílio do Google Earth, os quais foram validados em campo.

O software Vissim de microssimulação de tráfego foi utilizado como ferramenta de análise. Os parâmetros de calibração utilizados neste trabalho foram: velocidade média, tempo de viagem e a Estatística GEH, que relaciona volumes alocados e contagens reais. Os dois primeiros sendo estabelecidos pela metodologia do HCM [3], e o último de acordo com sua equação típica estabelecida pelo seu criador Geoffrey E. Havers [4]. 
Após a calibração, foi inserido o cenário proposto. Parâmetros como velocidade média, tempo de viagem, fila e saturação foram extraídos do software para futura comparação desses indicadores.

\section{Resultados esperados/Conclusóes}

Com o presente estudo, a equipe espera demonstrar o impacto da implantação de um mini-terminal de transporte público na região, estrutura inexistente na cidade de Curitiba, que espera-se reduzir o número de conflitos de trânsitos existentes, o que pode inferir em uma menor periculosidade da travessia da Avenida.

\section{Referências}

[1] VASCONCELLOS, E. A. Políticas de Transporte no Brasil: a construção da mobilidade excludente. 1. ed. Barueri, SP: Editora Manole, 2014.

[2] HELlingA, B. R. Requirements for the Calibration of Traffic Simulation Models. Canadian Society of Civil Engineering, University of Waterloo, Waterloo, Canadá, 1998.

[3] TRB. Highway Capacity Manual 2000. Transportation Reseach Board, Washington, D.C., 2000.

[4] FELDMAN, O. The GEH Measure and Quality of the Highway Assignment Models. Association for European Transport and Contributors, London, 2012. 